\title{
How Does Emotional Labor Influence Voice Behavior? The Roles of Work Engagement and Perceived Organizational Support
}

\author{
Yuechao Du* ${ }^{*}$ and Zhongming Wang \\ School of Management, Zhejiang University, Hangzhou 310058, China; zmwang_zju@hotmail.com \\ * Correspondence: ycdu@zju.edu.cn
}

\section{check for} updates

Citation: Du, Y.; Wang, Z. How Does Emotional Labor Influence Voice Behavior? The Roles of Work Engagement and Perceived Organizational Support. Sustainability 2021, 13, 10524. https://doi.org/ $10.3390 /$ su131910524

Academic Editors: Sarah Riforgiate, Shawna Malvini Redden,

Satoris Howes, Tim Huffman and Stacy Tye-Williams

Received: 31 August 2021

Accepted: 21 September 2021

Published: 22 September 2021

Publisher's Note: MDPI stays neutral with regard to jurisdictional claims in published maps and institutional affiliations.

Copyright: (c) 2021 by the authors. Licensee MDPI, Basel, Switzerland. This article is an open access article distributed under the terms and conditions of the Creative Commons Attribution (CC BY) license (https:/ / creativecommons.org/licenses/by/ $4.0 /)$.

\begin{abstract}
Promoting employee voice behavior is important for the sustainable development of organizations. Drawing on conservation of resources theory, the study examined the association between emotional labor and employee voice behavior and the mediation of work engagement in this relationship. Surveys were collected at two time points, four weeks apart, from 629 employees in the service industry in China. The results show that surface acting is negatively related to work engagement and that deep acting is positively related to work engagement. Employees' work engagement is positively associated with voice behavior. Hence, work engagement appears to be a mediating variable that translates the emotional labor into voice behavior. Moreover, perceived organizational support moderates the relationship between emotional labor and voice behavior. The theoretical and practical implications of these findings are discussed.
\end{abstract}

Keywords: emotional labor; deep acting; surface acting; work engagement; voice behavior; perceived organizational support

\section{Introduction}

As competition in the service industry intensifies, enterprises have increasingly higher demands for their employees' work attitudes, behaviors and service quality in order to achieve sustainable development. Sustainable development aims to balance economic, social and environmental development to ensure a better and sustainable future for all. Enterprises are key actors in the operation and integration of sustainability and, consequently, in addressing current and future stakeholder needs and contributing to the achievement of sustainable development for society at large [1]. However, enterprises experiencing success need to maximize their contributions for those aims. At present, service-oriented enterprises pay great attention to how to ensure employees' emotional labor has a beneficial impact on organizations [2]. Hochschild defined emotional labor as an individual's display of appropriate facial expressions or body movements to the public by disguising and managing internal and external emotional experiences according to the rules of expression required by the organization [3]. Morris and Feldman considered emotional labor to be the behavior and corresponding psychological process of displaying appropriate emotions during interactions with customer [4]. Emotional labor strategies include surface acting and deep acting [3,4]. Surface acting refers to the act of changing external display to show emotions without changing inner feelings, which is a kind of pretend emotional display [5]. Deep acting means that when the emotions felt by the individual are inconsistent with the emotions required to be displayed, the individual tries to change their feelings to be consistent with the role they are required to display $[5,6]$. Previous literature on emotional labor has focused on the relation between emotional labor and attitudinal or cognitive outcomes $[7,8]$, but few empirical studies have focused on behaviors caused by emotional labor. Of the few studies that have been conducted, Becker et al. found that deep acting positively promotes employees' extra-role behaviors through the mediating role of team 
support, while surface acting negatively affects extra-role behaviors [9]. Cheung and Lun pointed out that that deep acting promotes extra-role behaviors through work engagement, whereas surface acting is not related to extra-role behaviors [10]. Based on these inconsistent results, we believe it is important to further investigate the effects and boundary conditions of emotional labor on employee behavior.

Employee voice behavior refers to the informal, casual, upward communication of employees' ideas, solutions or concerns about work-related problems [11]. It is a proactive extra-role behavior aimed at improving the current situation [12]. Numerous studies have confirmed that voice behavior is an important way for enterprises to improve efficiency [11-14]. Employee voice behavior is also essential for leaders to learn information about cutting-edge market dynamics $[15,16]$. Employee voice behavior is positively correlated with work performance and organizational effectiveness [17-19]. Due to the potential benefits, scholars have turned their attention to promoting voice behavior in organizations [11]. Although there are numerous studies that have made useful attempts to examine the antecedents of employee voice behavior [20], little attention has been given to the role of emotional labor in promoting or hindering voice behavior. Prior studies have shown that employees' attitudinal and cognitive changes triggered by emotional labor have an impact on extra-role behavior [21]. As a typical extra-role behavior [12], voice behavior is likely to also be influenced by emotional labor.

Our study attempts to explore the influence of emotional labor on voice behavior based on conservation of resources (COR) theory. Conservation of resources theory suggests that people always actively tend to obtain, maintain and protect valuable resources while striving to avoid any threats that might cause resource depletion [22]. In view of conservation of resources theory, employees need to continuously monitor and adjust their external display of emotions such as expressions, speech and posture during emotional labor. Therefore, emotional labor depletes individuals' cognitive and emotional resources [23]. The consumption of these resources can be compensated by obtaining a salary, establishing good interactions with customers and receiving organizational support [24]. If resource consumption is greater than resource compensation, emotional labor has a negative impact, causing emotional exhaustion, emotional disorders, stress and burnout [25-28], leading to a decrease in work engagement. Conversely, if resource compensation is greater than resource consumption, emotional labor will have a positive impact, allowing for employees to have higher work engagement [29]. Employees with high work engagement tend to have stronger willingness to be involved in voice behavior [30].

This study analyzes responses from hotel service personnel to examine the mechanism of emotional labor on employee voice behavior and to explore the moderating effect of perceived organizational support. Based on an empirical test of the research model, our study offers implications for the research on emotional labor and voice behavior. First, the study examines the effect of emotional labor on employee voice behavior based on conservation of resources theory, which indicates that emotional labor not only affects employees' attitudinal and cognitive outcomes [7] but also affects employees' behavior. Second, this study examines the mediating role of work engagement in the relationship between emotional labor and voice behavior. By doing so, we extend the theoretical understanding of how and why different emotional labor strategies are related to employee voice behavior. Third, we investigate perceived organizational support as a boundary condition that moderates the psychological and behavioral consequences of surface acting and deep acting. Finally, the study of the relationship between emotional labor and employee voice behavior helps enterprises have a deeper understanding of employees' emotional labor so that they can develop corresponding management measures to achieve effective guidance and promote employee voice behavior for the sustainable development of both enterprises and employees. 


\section{Literature Review and Hypothesis Development}

\subsection{Emotional Labor and Employee Voice Behavior}

Hochschild defined emotional labor as an individual's display of appropriate facial expressions or body movements to the public by disguising and managing internal and external emotional experiences in accordance with the organization's rules [3]. Grandey proposed two specific strategies of emotional labor, namely, surface acting and deep acting [31]. Surface acting refers to the external expressions of emotions, such as intonation, posture and expressions that are adjusted to demonstrate emotions conforming to organizational rules [23]. The inconsistency between inner feelings and emotional expressions in surface acting may lead to impaired psychological well-being and lower job satisfaction [25]. Deep acting involves adjusting the external performance by trying to change the internal feelings to show emotional feelings that are consistent with the organization's expectations [23]. Individuals who adopt deep acting try to adjust their real emotions and focus on things that inspire positive feelings [32]. They also reevaluate things that generate negative emotions such as anger and frustration so that they can experience emotions that are consistent with the organization's expectation, which will improve the individual's job satisfaction [32]. The negative effects of emotional labor are mainly due to surface acting [25]. Multiple studies have found that surface acting can bring emotional exhaustion [25,26,33], emotional disorders [34], stress [35] and job dissatisfaction [36] and can decrease work engagement [29]. In contrast to surface acting, deep acting is positively related to employees personal accomplishment, job satisfaction and job performance [31,32,37].

Conservation of resources theory explains why emotional labor has different effects by proposing that people always try to maintain valuable resources and avoid losing resources [23]. Hobfoll pointed out that resources include physical energy, emotional energy and cognitive energy [24]. Both surface acting and deep acting consume resources, but there are differences in the amount of resources consumed and the impact on the outcome variables. Specifically, surface acting consumes more psychological resources. Surface acting adjusts the emotional response by pretending to have positive emotions or suppressing negative emotions. There are more inconsistencies between emotional experience and expression, and managing emotional disorders requires more psychological resources [23]. Long-term emotional disorders will lead to negative mental states such as depersonalization and derealization. When the psychological resources cannot be compensated in time, it will lead to more resource consumption [33]. On the other hand, employees may acquire more psychological resources through deep acing. Deep acting focuses on adjusting the real feelings inside, and there is consistency between emotional experience and expression, thus consuming fewer psychological resources [32]. By expressing the real emotions during deep acting, the individual is able to reevaluate the events that generate the negative emotions and actively adjust to the positive emotions. The resulting positive emotions, such as a sense of accomplishment and self-affirmation, make it more likely that the individual will be compensated for resource consumption. So, deep acting is a resource-acquisition process [38].

Voice behavior refers to the discretionary, informal and upward communication of employees' desire to improve their existing work patterns, methods or processes, and it is also an important way for teams to effectively cope with complexity and promote performance [11]. According to conservation of resources theory, resource conservation and resource acquisition are two processes during emotional labor. Resource conservation emphasizes that individuals have a strong motivation to protect existing resources from further exhaustion [17]. Resource acquisition emphasizes that the individual will invest more resources to prevent further loss of resources [22]. Specifically, when engaging in surface acting, since resource loss is more prominent than resource gain [23], employees have a strong incentive to protect their remaining resources from further loss and to avoid investing resources such as time and energy in areas with limited benefits, thus reducing voice behavior to avoid further resource loss [30]. When employees engage in deep acting, they are able to obtain more psychological resources, which drives employees from 
resource conservation to resource acquisition. Therefore, the process motivates employees to increase voice behavior to acquire additional resources [17].

Hypothesis 1a. Surface acting is negatively related to voice behavior.

Hypothesis $\mathbf{1 b}$. Deep acting is positively related to voice behavior.

\subsection{Mediating Effects of Work Engagement}

Work engagement is a positive and fulfilling emotional and cognitive state characterized by vigor, dedication and absorption [39]. Vigor is manifested by high energy and resilience, willingness to work hard and perseverance in the face of difficulties. Dedication is characterized by a sense of enthusiasm, meaningfulness and inspiration. Absorption is demonstrated by being deeply immersed in one's work, which makes it difficult to extricate from it [39]. When employees engage in surface acting, they will experience emotional dissonance due to the difference between emotional expression and inner feelings [33]. If employees are chronically dissonant, they may neither integrate themselves with their job role nor find meaning and value of their work, which will lead to diminished motivation [40]. In addition, according to conservation of resources theory, surface acting represents great resource consumption [23]. The more resources used to disguise one's emotions, the less resources are available to perform job duties. When employees' feelings are not consistent with the displayed role, it can lead to emotional exhaustion [41]. Studies have also found that emotional disorders are associated with emotional exhaustion [42,43]. Thus, surface acting leads to emotional disorder, which can decline employees' work engagement. In contrast, deep acting reduces emotional disorder by aligning emotion with expression [44]. Employees who engage in deep acting are more motivated to do the work they enjoy. There is consistency between the emotions they feel and the emotions they express, which motivates them to generate more vigor, thereby enhancing work engagement [29].

The improvement of employees' work engagement will lead to higher job satisfaction, lower turnover rates and better work performance [45,46]. Employees with higher work engagement are more proactive in improving themselves and avoiding deviant workplace behavior [47]. Demerouti et al. noted that employees with high work engagement tend to exhibit more extra-role behaviors such as voice behavior [48]. Kahn identified work engagement as the expression of "the preferred self" [49]. In this context, self-expression refers to the display of one's real thoughts and feelings, which is closely related to employee voice behavior [50]. Work engagement implies active working, role expansion and working beyond expectations [39]. In other words, employees with high work engagement are able to accomplish tasks within their roles with less effort, so they have the ability to devote more resources to promote the better development of the organization [40]. Schmitt et al. stated that work engagement involves the use of personal resources, which are necessary for voice behavior [51]. At the same time, employees with high work engagement value their work, and they are motivated to work hard to make their working conditions more satisfying [40]. Compared to employees with lower work engagement, employees with higher work engagement are more attached to the organization and have more positive attitudes toward work, which increases their willingness to engage in voice behavior [52].

Hypothesis 2a. Work engagement mediates the negative relationship between surface acting and voice behavior.

Hypothesis $\mathbf{2} \mathbf{b}$. Work engagement mediates the positive relationship between deep acting and voice behavior. 


\subsection{Moderating Effects of Perceived Organizational Support}

Perceived organizational support is the degree to which employees perceive that the organization values their contributions and cares about their well-being at work [53]. Employees experience a range of positive emotions due to the organization's commitment to them [54]. This positive emotion can help restore employees' emotional resources during emotional labor [55]. Previous studies have found that high perceived organizational support promotes employees' proactive behavior [56], work engagement [57] and job satisfaction [58]. Organizational support is an important external resource for employees. The acquisition of these resources partially offsets resource depletion due to emotional labor and contributes to emotional recovery, thus moderating the relationship between emotional labor and outcome variables [49]. Previous studies have also shown that perceived organizational support can effectively curb the accumulation of negative emotions and minimize the gap between employees' real emotions and the emotions required for work, thus reducing employees' emotional dissonance [59]. It can be inferred that when employees' perceived organizational support is high, the negative impact of surface acting on work engagement will be weakened, while the positive impact of deep acting on work engagement will be enhanced. According to conservation of resources theory, when employees gradually lose energy due to continuous efforts while working, the lack of appropriate internal resources or external resources will lead them to job burnout [23]. However, external resources, such as perceived organizational support, can reduce the stress and resource depletion caused by surface acting and therefore lower the negative impact of surface acting on work engagement. This supplementation of external resources can increase employees' resources, thereby promoting the positive impact of deep acting on work engagement. Thus, perceived organizational support can strengthen the positive relationship of deep acting on work engagement and weaken the negative relationship of surface acting on work engagement. Figure 1 shows the proposed model.

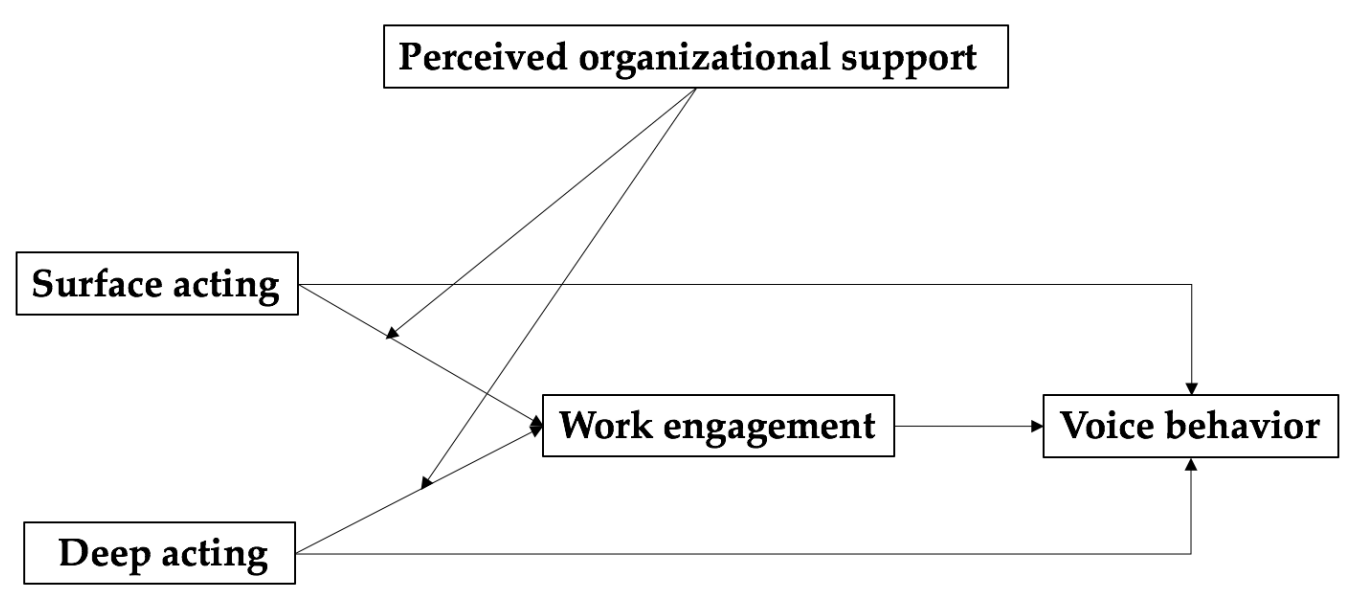

Figure 1. Proposed model.

Hypothesis 3a. Perceived organizational support moderates the negative relationship between surface acting and work engagement in that the higher the perceived organizational support is, the weaker the negative relationship is between surface acting and work engagement.

Hypothesis $\mathbf{3 b}$. Perceived organizational support moderates the positive relationship between deep acting and work engagement in that the higher the perceived organizational support is, the stronger the positive relationship is between deep acting and work engagement. 


\section{Method}

\subsection{Data Collection and Study Sample}

The research sample includes frontline employees from 62 hotels in Zhejiang and Shanghai. In our study, frontline staff refers to those whose work involves direct contact with customers and the provision of services that customers need [59], mainly including frontline staff, concierge staff and catering staff. The job characteristics of frontline hotel staff meet the following two characteristics of emotional labor. First, they need to have extensive interaction with customers. Second, employees must comply with the organization's rules of emotional expression to show an appropriate emotional state $[60,61]$.

The study used questionnaires to collect data, and a 5-point Likert scale $(1=$ completely disagree/never; $5=$ completely agree/always) was used to ask about the level of agreement. Since the scale was a foreign scale, the English scale was translated into Chinese by the researcher in a double-blind way before measurement. We then further analyzed the translated sentences that differed significantly from the original scale and corrected them. Then, we asked experts in the relevant field to evaluate and test the items separately. Finally, before the formal research, a prestudy was conducted with frontline employees, in which they were asked whether they had any questions about the scale items. On this basis, some of the scale items were revised in terms of language and expressions. The results of the prestudy showed that the adopted scales had good reliability. Through the above methods, the reliability and validity of the questionnaire were confirmed, and the final survey scale was formed.

Data were collected at two time points (four weeks between time 1 and time 2) to limit common method variance [62]. At the first measurement point (T1), employees self-reported their emotional labor strategies and perceived organizational support. They also provided information about their general demographic characteristics, such as gender, age, education level and organizational tenure. At the second measurement point (T2), employees who completed the first round of the questionnaire were asked to rate their work engagement and voice behavior. A total of 629 valid questionnaires remained after questionnaires with incomplete answers were removed, representing a response rate of $70.3 \%$.

Of these participants, 341 were women (54.2\%) and 288 were men (45.8\%). High school graduates and those with less education accounted for $48.0 \%(n=302)$ of the total, $50.4 \%(n=317)$ were junior college graduates and $1.6 \%(n=10)$ were university graduates. The tenure of the participants was as follows: less than 1 year $(17.8 \%), 1-5$ years $(36.6 \%)$, $6-10$ years $(25.3 \%), 11-15$ years $(13.5 \%)$ and more than 15 years $(6.8 \%)$. The age distribution was primarily between 21 and 30 years old, representing $51.8 \%$ of the sample.

\subsection{Measurement Scales}

Emotional labor. We use the 8-item Emotional Labor Strategies Scale developed and tested by Brotheridge and Lee [23] and Grandey [63]. Among them, 5 items measure surface acting and 3 items measure deep acting. All questions were assessed on a 5-point scale from "strongly disagree" to "strongly agree." The alpha reliability of surface acting was 0.83 and that of deep acting was 0.82 .

Work engagement. Using the Utrecht Engagement Scale (UWS-9) [36]. The scale is divided into three dimensions: vigor, dedication and absorption. Examples include "At my work, I feel bursting with energy" for vigor; "I am enthusiastic about my job" for dedication; "I feel happy when I am working intensely" for absorption. All questions were assessed on a 5-point scale from "strongly disagree" to "strongly agree." The alpha reliability of this scale was 0.87 .

Perceived organizational support. Perceived organizational support was measured using an 8-item scale developed by Eisenberg et al. [64]. Example items are "My organization considers my goals and values" and "When I have a problem, my organization can help". A 5-point Likert scale was used for the measurement $(1=$ strongly disagree, $5=$ strongly agree). The alpha reliability of this scale was 0.87 . 
Employee voice behavior. The 10-item voice behavior scale developed by Liang et al. [65] was used to evaluate voice behavior. Respondents answered a set of Likert scale questions ( 1 = strongly disagree, 5 = strongly agree). An example includes the following: "I proactively voice out constructive suggestions that help the unit reach its goals". The alpha reliability of this scale was 0.84 .

Control variables. Previous studies have shown that age and gender may affect the experience of emotional labor [66]. The level of education and organizational tenure were correlated with voice behavior [65] and work engagement [30]. Thus employees' age, gender, educational level and organizational tenure were treated as control variables.

\section{Results}

\subsection{Descriptive Statistics}

Table 1 presents the means, standard deviations and Pearson correlations of all variables. As shown in the table, surface acting was negatively correlated with work engagement $(r=-0.10, p<0.01)$ and voice behavior $(r=-0.21, p<0.01)$, while deep acting was positively related to work engagement $(r=0.25, p<0.01)$ and voice behavior $(r=0.35$, $p<0.01)$. Work engagement is positively correlated with voice behavior $(r=0.42, p<0.01)$. These results provided preliminary support for our hypotheses.

Table 1. Mean value, standard deviation and correlation of all variables $(\mathrm{N}=629)$.

\begin{tabular}{|c|c|c|c|c|c|c|c|c|c|c|}
\hline & Mean & SD & 1 & 2 & 3 & 4 & 5 & 6 & 7 & 8 \\
\hline 1. Gender & 0.54 & 0.51 & & & & & & & & \\
\hline 2. Age & 29.91 & 7.47 & $-0.13^{* *}$ & & & & & & & \\
\hline 3. Organizational tenure & 6.20 & 5.11 & $-0.31^{* *}$ & $0.48^{* *}$ & & & & & & \\
\hline 4. Education & 1.54 & 0.53 & 0.05 & $-0.36^{* *}$ & $-0.20^{* *}$ & & & & & \\
\hline 5. Surface acting & 3.19 & 0.81 & -0.02 & 0.05 & -0.02 & 0.05 & & & & \\
\hline 6. Deep acting & 3.95 & 0.72 & $0.12^{* *}$ & $0.19^{* *}$ & 0.05 & $-0.11^{* *}$ & -0.08 & & & \\
\hline 7. Work engagement & 4.30 & 0.54 & -0.02 & $0.10 *$ & $0.09 *$ & 0.04 & $-0.10 *$ & $0.25^{* *}$ & & \\
\hline 8. Organizational support & 4.06 & 0.65 & $-0.08 *$ & $0.14^{* *}$ & 0.05 & -0.08 & $-0.15^{* *}$ & $0.51^{* *}$ & $0.41^{* *}$ & \\
\hline 9. Voice behavior & 3.98 & 0.57 & -0.05 & $0.20^{* *}$ & $0.12^{* *}$ & $-0.10 *$ & $-0.21^{* *}$ & $0.35^{* *}$ & $0.42^{* *}$ & $0.51^{* *}$ \\
\hline
\end{tabular}

Note: ${ }^{*} p<0.05 ;{ }^{* *} p<0.01$. Gender: male $=0$; female $=1$.

\subsection{Confirmatory Factor Analysis}

Before testing our hypotheses, we conducted a series of confirmatory factor analyses to examine the measurement model fit and the distinctiveness among the variables. The results of the tests are shown in Table 2. The five-factor measurement model had the best goodness of fit $(\chi 2 / d f=2.89$, comparative fit index $(\mathrm{CFI})=0.94$, Tucker-Lewis index $(\mathrm{TLI})=0.93$, root mean square error of approximation $($ RMSEA $)=0.05$, standardized root mean square residual $(S R M R)=0.04)$. Compared with the five-factor model, a four-factor model combining surface acting and deep acting into one construct did not fit the data well $(x 2 / d f=5.56, \mathrm{CFI}=0.89, \mathrm{TLI}=0.87, \mathrm{RMSEA}=0.10, \mathrm{SRMR}=0.07)$. As shown in Table 2, the results illustrate that the five-factor model fits the data substantially better than any other model [67]. Thus, the uniqueness of the five constructs in this study is supported. Given these results, all five constructs were applied in further analyses.

Table 2. Results of confirmatory factor analysis $(\mathrm{N}=629)$.

\begin{tabular}{lccccc}
\hline & $\chi 2 / d f$ & CFI & TLI & RMSEA & SRMR \\
\hline Hypothesized five-factor model & 2.89 & 0.94 & 0.93 & 0.05 & 0.04 \\
Four-factor model [Combine SA and DA] & 5.56 & 0.89 & 0.87 & 0.10 & 0.07 \\
Four-factor model [Combine POS and VB] & 7.63 & 0.84 & 0.80 & 0.10 & 0.06 \\
Four-factor model [Combine WE and POS] & 8.66 & 0.81 & 0.77 & 0.11 & 0.07 \\
Four-factor model [Combine WE and VB] & 12.10 & 0.73 & 0.67 & 0.13 & 0.06 \\
\hline
\end{tabular}


Table 2. Cont.

\begin{tabular}{|c|c|c|c|c|c|}
\hline & $\chi^{2 / d f}$ & CFI & TLI & RMSEA & SRMR \\
\hline Four-factor model [Combine SA and DA; POS and WE] & 10.34 & 0.76 & 0.72 & 0.12 & 0.09 \\
\hline Three-factor model [Combine SA, DA and POS] & 5.56 & 0.79 & 0.87 & 0.09 & 0.07 \\
\hline Three-factor model [Combine SA, DA and WE] & 8.75 & 0.70 & 0.77 & 0.11 & 0.09 \\
\hline Two-factor model [Combine SA, DA, POS and WE] & 11.56 & 0.73 & 0.69 & 0.13 & 0.09 \\
\hline One-factor model [all variables combined] & 17.29 & 0.58 & 0.52 & 0.16 & 0.08 \\
\hline
\end{tabular}

Note: SA = surface acting; DA = deep acting; WE = work engagement; POS = perceived organizational support; $\mathrm{VB}=$ voice behavior.

\subsection{Hypothesis Test}

Mixed regression models were run to test the hypotheses in separate steps following Baron and Kenny's approach [68]. To test Hypothesis 1, we regressed voice behavior on gender, age, organizational tenure and education together (Model 7, Table 3) and then surface acting and deep acting additionally (Model 8, Table 3). As predicted in Hypothesis $1 \mathrm{a}$, the relationship between surface acting and voice behavior was negative $(b=-0.13$, $p<0.01)$. Additionally, as predicted in Hypothesis $1 \mathrm{~b}$, the relationship between deep acting and voice behavior was positive $(b=0.26, p<0.01)$ while controlling for gender, age, organizational tenure and education. Hypothesis $1 \mathrm{a}$ and Hypothesis $1 \mathrm{~b}$ were supported. Surface acting is negatively related to voice behavior, while deep acting is positively related to voice behavior.

Table 3. Results of mixed models $(\mathrm{N}=629)$.

\begin{tabular}{|c|c|c|c|c|c|c|c|c|c|}
\hline \multirow[t]{2}{*}{ DV } & \multicolumn{6}{|c|}{ Work Engagement } & \multicolumn{3}{|c|}{ Voice Behavior } \\
\hline & M1 & M2 & M3 & M4 & M5 & M6 & M7 & M8 & M9 \\
\hline \multicolumn{10}{|l|}{$\mathrm{CV}$} \\
\hline Gender & 0.01 & -0.04 & -0.04 & -0.05 & -0.04 & -0.05 & -0.03 & $-0.09 *$ & -0.07 \\
\hline Age & 0.01 & 0.01 & 0.01 & 0.01 & 0.01 & 0.01 & 0.01 & $0.01 * *$ & $0.01 * *$ \\
\hline OT & 0.01 & 0.01 & 0.01 & 0.01 & 0.01 & 0.01 & 0.01 & 0.01 & -0.01 \\
\hline $\begin{array}{l}\text { Education } \\
\text { IV }\end{array}$ & \multicolumn{8}{|c|}{ IV } & 0.42 \\
\hline SA & & $-0.06^{*}$ & -0.03 & -0.11 & -0.03 & -0.10 * & & $-0.13^{* *}$ & $-0.11^{* *}$ \\
\hline DA & & $0.18^{* *}$ & 0.01 & 0.01 & $0.13 *$ & 0.11 * & & $0.26^{* *}$ & $0.19^{* *}$ \\
\hline \multicolumn{10}{|l|}{ Moderator } \\
\hline POS & & & $0.34^{* *}$ & $0.59^{* *}$ & 0.02 & 0.23 & & & \\
\hline \multicolumn{10}{|l|}{ Interaction } \\
\hline SA*POS & & & & $0.07 *$ & & 0.08 * & & & \\
\hline DA*POS & & & & & 0.09 * & 0.10 * & & & \\
\hline \multicolumn{10}{|l|}{ Mediator } \\
\hline WE & & & & & & & & & $0.36^{* *}$ \\
\hline $\mathrm{R}^{2}$ & 0.02 & 0.08 & 0.19 & 0.19 & 0.21 & 0.2 & 0.04 & 0.19 & 0.29 \\
\hline $\mathrm{F}^{2}$ & 3.15 * & $8.43^{* *}$ & $18.24^{* *}$ & $15.71^{* *}$ & $21.15^{* *}$ & $19.67^{* *}$ & $7.18 *$ & $19.44^{* *}$ & $40.02 * *$ \\
\hline
\end{tabular}

Note: $\mathrm{OT}$ = organizational tenure; $\mathrm{SA}$ = surface acting; $\mathrm{DA}$ = deep acting; $\mathrm{WE}=$ work engagement; $\mathrm{POS}$ = perceived organizational support. ${ }^{*} p<0.05 ;{ }^{* *} p<0.01$.

To test the mediating effect of work engagement (Hypotheses 2a and 2b), we performed a Sobel test to examine the indirect effects of surface acting and deep acting on voice behavior through work engagement. As shown in Table 4, there were significant unconditional indirect effects of surface acting (estimate $=-0.02, p<0.01,95 \% \mathrm{CI}[-0.038$, $-0.002]$ ) and deep acting (estimate $=0.06, p<0.01,95 \%$ CI $[0.036,0.096]$ ) on voice behavior through work engagement. Hence, work engagement mediated the negative relationship between surface acting and voice behavior and mediated the positive relationship between deep acting and voice behavior. Thus, hypotheses $2 \mathrm{a}$ and $2 \mathrm{~b}$ were supported. 
Table 4. Results of mediating effects.

\begin{tabular}{ccccc}
\hline & IV $\rightarrow$ Me (Path a) & Me $\rightarrow$ DV (Path b) & IV $\rightarrow$ DV & Indirect Effect (a*b) \\
\hline $\mathbf{S A ~} \rightarrow$ WE $\rightarrow$ VB & $-0.06^{*}$ & \multirow{2}{*}{$0.36^{* *}$} & $-0.11^{* *}$ & $-0.02^{* *}, 95 \% \mathrm{CI}=[-0.038,-0.002]$ \\
$\mathbf{D A} \rightarrow \mathbf{W E} \rightarrow$ VB & $0.18^{* *}$ & $0.19^{* *}$ & $0.06^{* *}, 95 \% \mathrm{CI}=[0.036,0.096]$ \\
\hline
\end{tabular}

Note: $\mathrm{SA}=$ surface acting; $\mathrm{DA}=$ deep acting; $\mathrm{WE}=$ work engagement; $\mathrm{VB}=$ voice behavior. ${ }^{*} p<0.05 ;{ }^{* *} p<0.01$.

Regarding hypotheses $3 a$ and $3 b$, we examined the moderating effect of perceived organizational support on the relationship between emotional labor and work engagement. As predicted, the results of Model 6 in Table 3 indicate that the interaction between surface acting and perceived organizational support significantly predicted work engagement $(b=0.08, p<0.05)$ and that the interaction between deep acting and perceived organizational support significantly predicted work engagement $(b=0.10, p<0.05)$. We used simple slopes to further analyze the interaction (see Figures 2 and 3). As shown in Figure 2, the negative relationship between surface acting and work engagement was weaker when perceived organizational support was higher, supporting hypothesis 3a. Moreover, as shown in Figure 3, the positive relationship between deep acting and work engagement was stronger when perceived organizational support was higher, supporting hypothesis $3 \mathrm{~b}$.

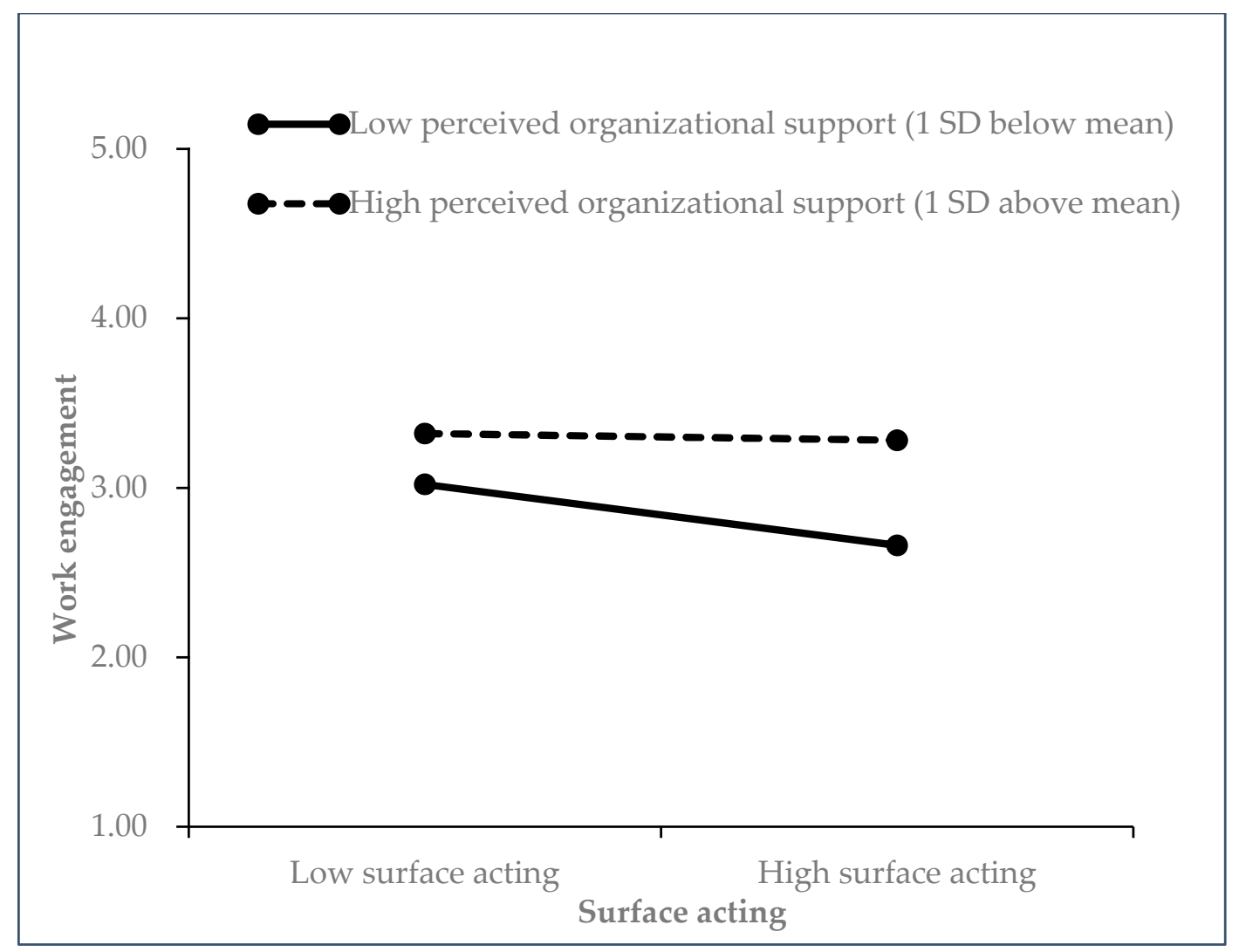

Figure 2. Interaction between surface acting and perceived organizational support on work engagement. 


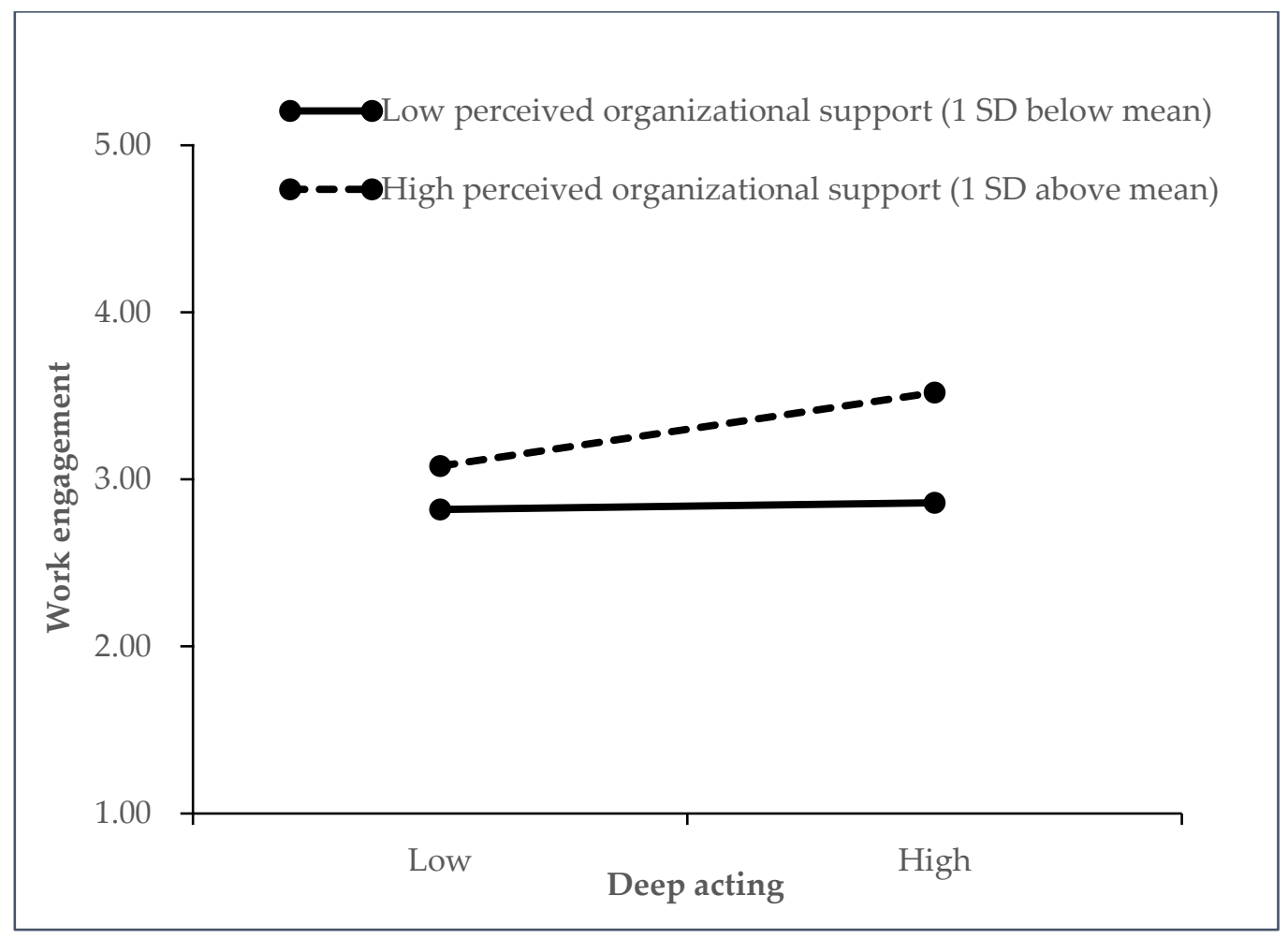

Figure 3. Interaction between deep acting and perceived organizational support on work engagement.

\section{Conclusions and Discussion}

This study provided support for a theoretical model of emotional labor and voice behavior. Work engagement predicted voice behavior and mediated the relationship between surface acting and voice behavior and between deep acting and voice behavior. Moreover, the negative relationship between surface acting and work engagement was weaker when the perceived organizational support was higher. In contrast, the positive relationship between deep acting and work engagement was stronger when the perceived organizational support was higher.

\subsection{Theoretical Implications}

Based on the existing literature on emotional labor and voice behavior, our study examined the effects of different emotional labor strategies on employee voice behavior and their boundary conditions. The theoretical contributions are mainly reflected in the following aspects. First, based on conservation of resources theory, we examined the effects of surface acting and deep acting on employee voice behavior, which expands our understanding of the effects of emotional labor on employee voice behavior. Specifically, the previous literature on emotional labor emphasized the effects of emotional labor on individuals' attitudinal and cognitive outcomes, such as work satisfaction and wellbeing $[37,42,43]$, but paid less attention to the behaviors induced by emotional labor. Our study found that surface acting can inhibit voice behavior, while deep acting can promote voice behavior.

Second, our research explains the mediating mechanism of how emotional labor affects employee voice behavior, which is a beneficial supplement to relevant studies. According to conservation of resources theory, people tend to retain the resources they need for their own development $[23,24]$. When the psychological resources of employees are not supplemented in a timely manner due to the consumption of surface acting, it may lead to a decrease in work engagement [40]. Employees who adopt deep acting have consistency between the emotions they feel and the emotions they express, which leads to an increase in their work engagement. At the same time, employees with high work engagement value 
their work more, and they are motivated to make their working conditions more satisfying, thus promoting their voice behaviors [48].

Finally, this study empirically tests the moderating role of perceived organizational support in the relationship between emotional labor and work engagement. According to conservation of resources theory, organizational support is an important external resource. The acquisition of these resources partially offsets resource depletion due to emotional labor and contributes to emotional recovery, thus moderating the relationship between emotional labor and work engagement [57]. We find that high levels of perceived organizational support can weaken the negative relationship between surface acting and work engagement and enhance the positive relationship between deep acting and work engagement.

\subsection{Management Implications}

First, since surface acting can lead to lower work engagement and affect employees' voice behavior, we suggest that service-oriented enterprises should actively adopt various approaches to strengthen employees' emotional labor training. In such enterprises, employees inevitably need to engage in emotional labor. Therefore, human resource departments should incorporate specific training into individual career development plans and organizational training programs. Through targeted training, frontline employees can improve their emotion management capabilities and reduce the impact of negative emotions.

Second, for service-oriented enterprises, it is necessary to set up a clear code for employees to maintain the consistency and effectiveness of such rules. Enterprises should clearly explain the service standards to employees and set up corresponding rewards and consequences. The human resource departments should also incorporate emotional labor into the compensation system, through which enterprises can compensate employees for the loss of psychological resources.

Leaders should recognize and leverage organizational support as a compensatory resource. Our findings indicate that organizational support, as an external resource, can effectively supplement the resource loss of due to emotional labor, thus weakening the negative relationship between surface acting and work engagement and strengthening the positive relationship between deep acting and work engagement. Human resource departments should pay attention to the social and emotional needs of employees. When designing standard work procedures, enterprises should create a fair organizational atmosphere and give employees more autonomy in their work. In particular, it is necessary to give supervisors more authority to support frontline employees.

\subsection{Limitations and Future Research}

This study used a time-lag research design, which somewhat reinforces the validity of causality, but since all measured variables are derived from employee self-evaluation, it is difficult to rule out the risk of homogeneity in the study [62]. Future studies could use other people's ratings or observations of the variables to confirm the results. In addition, this study used questionnaires to collect data, which is slightly deficient in the representation of causality. Future research can expand the sample size of the questionnaire survey and adopt multiple data sources to strengthen the generalizability of the study.

Our study used the averaging item method to obtain a final average score, thus exploring only the mediating role of work engagement as a single variable. Future research could specifically explore the role of different dimensions of work engagement. Since the averaging item method may lose some information and variance [59], future studies may explore in depth which dimension of work engagement is affected by emotional labor and which dimension of work engagement specifically affects employee voice behavior. In addition, the influence of emotional labor on other behaviors, such as proactive behavior and organizational citizenship behavior, can be explored to better understand the influential mechanism of emotional labor.

During the COVID-19 pandemic, service industries experienced a severe decline in revenue and a significant increase in employee turnover rate. Although the COVID-19 
pandemic has caused an unprecedented impact on the traditional service industry, its impact on the digital service industry is very limited. The digital transformation has mitigated the impact of the COVID-19 pandemic on service industries, while providing new opportunities for digital services. Future research can also explore the research topic in the context of COVID-19 and digital transformation (Industry 4.0).

Author Contributions: Y.D., as the first author, proposed the idea and basic model for this research, collected and analyzed the data and drafted the work. Z.W. supervised this research and helped revise it. Both authors have read and agreed to the published version of the manuscript.

Funding: This research received no external funding.

Institutional Review Board Statement: Not applicable.

Informed Consent Statement: Not applicable.

Data Availability Statement: Not applicable.

Conflicts of Interest: The authors declare no conflict of interest.

\section{References}

1. Fonseca, L.M.; Domingues, J.P.; Dima, A.M. Mapping the sustainable development goals relationships. Sustainability 2020, 12, 3359. [CrossRef]

2. Shani, A.; Uriely, N.; Reichel, A.; Ginsburg, L. Emotional labor in the hospitality industry: The influence of contextual factors. Int. J. Hosp. Manag. 2014, 37, 150-158. [CrossRef]

3. Ashforth, B.E.; Humphrey, R.H. Emotional labor in service roles: The influence of identity. Acad. Manag. Rev. 1993, 18, 88-115. [CrossRef]

4. Morris, J.A.; Feldman, D.C. The dimensions, antecedents, and consequences of emotional labor. Acad. Manag. Rev. 1996, 21, 986-1010. [CrossRef]

5. Diefendorff, J.M.; Croyle, M.H.; Gosserand, R.H. The dimensionality and antecedents of emotional labor strategies. J. Vocat. Behav. 2005, 66, 339-357. [CrossRef]

6. Humphrey, R.H.; Ashforth, B.E.; Diefendorff, J.M. The bright side of emotional labor. J. Organ. Behav. 2015, 36, 749-769. [CrossRef]

7. Spencer, S.; Rupp, D.E. Angry, guilty, and conflicted: Injustice toward coworkers heightens emotional labor through cognitive and emotional mechanisms. J. Appl. Psychol. 2009, 94, 429-444. [CrossRef]

8. Shapoval, V. Organizational injustice and emotional labor in the hospitality industry: A theoretical review. Int. J. Hosp. Manag. 2019, 83, 56-64. [CrossRef]

9. Becker, W.J.; Cropanzano, R.; Van Wagoner, P.; Keplinger, K. Emotional labor within teams: Outcomes of individual and peer emotional labor on perceived team support, extra-role behaviors, and turnover intentions. Group Organ. Manag. 2018, 43 , 38-71. [CrossRef]

10. Cheung, F.Y.; Lun, V.M.C. Relation between emotional labor and organizational citizenship behavior: An investigation among Chinese teaching professionals. J. Gen. Psychol. 2015, 142, 253-272. [CrossRef]

11. Morrison, E.W. Employee voice and silence. Annu. Rev. Organ. Psychol. Organ. Behav. 2014, 1, 173-197. [CrossRef]

12. Van Dyne, L.; LePine, J.A. Helping and voice extra-role behaviors: Evidence of construct and predictive validity. Acad. Manag. J. 1998, 41, 108-119.

13. LePine, J.A.; Van Dyne, L. Predicting voice behavior in work groups. J. Appl. Psychol. 1998, 83, 853-868. [CrossRef]

14. Duan, J.; Li, C.; Xu, Y.; Wu, C.H. Transformational leadership and employee voice behavior: A Pygmalion mechanism. J. Organ. Behav. 2017, 38, 650-670. [CrossRef]

15. McClean, E.J.; Martin, S.R.; Emich, K.J.; Woodruff, C.T. The social consequences of voice: An examination of voice type and gender on status and subsequent leader emergence. Acad. Manag. J. 2018, 61, 1869-1891. [CrossRef]

16. Weiss, M.; Morrison, E.W. Speaking up and moving up: How voice can enhance employees' social status. J. Organ. Behav. 2019, 40,5-19. [CrossRef]

17. Ng, T.W.; Feldman, D.C. Employee voice behavior: A meta-analytic test of the conservation of resources framework. J. Organ. Behav. 2012, 33, 216-234. [CrossRef]

18. Lam, C.F.; Mayer, D.M. When do employees speak up for their customers? A model of voice in a customer service context. Pers. Psychol. 2014, 67, 637-666. [CrossRef]

19. Frazier, M.L.; Bowler, W.M. Voice climate, supervisor undermining, and work outcomes: A group-level examination. J. Manag. 2015, 41, 841-863. [CrossRef]

20. Crant, J.M.; Kim, T.Y.; Wang, J. Dispositional antecedents of demonstration and usefulness of voice behavior. J. Bus. Psychol. 2011, 26, 285-297. [CrossRef]

21. Little, L.M.; Gooty, J.; Williams, M. The role of leader emotion management in leader-member exchange and follower outcomes. Leadersh. Q. 2016, 27, 85-97. [CrossRef] 
22. Hobfoll, S.E. Conservation of resources: A new attempt at conceptualizing stress. Am. Psychol. 1989, 44, 513. [CrossRef]

23. Brotheridge, C.M.; Lee, R.T. Testing a conservation of resources model of the dynamics of emotional labor. J. Occup. Health Psychol. 2002, 7, 57-67. [CrossRef]

24. Hobfoll, S.E.; Halbesleben, J.; Neveu, J.P.; Westman, M. Conservation of resources in the organizational context: The reality of resources and their consequences. Annu. Rev. Organ. Psychol. Organ. Behav. 2018, 5, 103-128. [CrossRef]

25. Grandey, A.A.; Kern, J.H.; Frone, M.R. Verbal abuse from outsiders versus insiders: Comparing frequency, impact on emotional exhaustion, and the role of emotional labor. J. Occup. Health Psychol. 2007, 12, 63-79. [CrossRef]

26. Hwa, M.A.C. Emotional labor and emotional exhaustion. J. Manag. Res. 2012, 12, 115-127.

27. Park, H.; Oh, H.; Boo, S. The Role of Occupational Stress in the Association between Emotional Labor and Mental Health: A Moderated Mediation Model. Sustainability 2019, 11, 1886. [CrossRef]

28. Sanchez-Gomez, M.; Breso, E. In pursuit of work performance: Testing the contribution of emotional intelligence and burnout. Int. J. Environ. Res. Public Health 2020, 17, 5373. [CrossRef]

29. Yoo, J.J.; Arnold, T.J. Customer orientation, engagement, and developing positive emotional labor. Serv. Ind. J. 2014, 34, 1272-1288. [CrossRef]

30. Cheng, J.W.; Lu, K.M.; Chang, Y.Y.; Johnstone, S. Voice behavior and work engagement: The moderating role of supervisorattributed motives. Asia Pac. J. Hum. Resour. 2013, 51, 81-102. [CrossRef]

31. Grandey, A.A. Emotional regulation in the workplace: A new way to conceptualize emotional labor. J. Occup. Health Psychol. 2000, 5, 95-110. [CrossRef]

32. Huang, J.L.; Chiaburu, D.S.; Zhang, X.A.; Li, N.; Grandey, A.A. Rising to the challenge: Deep acting is more beneficial when tasks are appraised as challenging. J. Appl. Psychol. 2015, 100, 1398-1408. [CrossRef] [PubMed]

33. Wang, K.L.; Groth, M. Buffering the negative effects of employee surface acting: The moderating role of employee-customer relationship strength and personalized services. J. Appl. Psychol. 2014, 99, 341-350. [CrossRef] [PubMed]

34. Zapf, D.; Holz, M. On the positive and negative effects of emotion work in organizations. Eur. J. Work Organ. Psychol. 2006, 15, 1-28. [CrossRef]

35. Hülsheger, U.R.; Lang, J.W.; Maier, G.W. Emotional labor, strain, and performance: Testing reciprocal relationships in a longitudinal panel study. J. Occup. Health Psychol. 2010, 15, 505-521. [CrossRef] [PubMed]

36. Giardini, A.; Frese, M. Reducing the negative effects of emotion work in service occupations: Emotional competence as a psychological resource. J. Occup. Health Psychol. 2006, 11, 63-75. [CrossRef] [PubMed]

37. Brotheridge, C.M.; Grandey, A.A. Emotional labor and burnout: Comparing two perspectives of "people work". J. Vocat. Behav. 2002, 60, 17-39. [CrossRef]

38. Mesmer-Magnus, J.R.; DeChurch, L.A.; Wax, A. Moving emotional labor beyond surface and deep acting: A discordance-congruence perspective. Organ. Psychol. Rev. 2012, 2, 6-53. [CrossRef]

39. Schaufeli, W.B.; Bakker, A.B.; Salanova, M. The measurement of work engagement with a short questionnaire: A cross-national study. Educ. Psychol. Meas. 2006, 66, 701-716. [CrossRef]

40. Mróz, J.; Kaleta, K. Relationships between personality, emotional labor, work engagement and job satisfaction in service professions. Int. J. Occup. Med. Environ. Health 2016, 29, 767-782. [CrossRef]

41. Li, J.J.; Wong, I.A.; Kim, W.G. Does mindfulness reduce emotional exhaustion? A multilevel analysis of emotional labor among casino employees. Int. J. Hosp. Manag. 2017, 64, 21-30. [CrossRef]

42. Karatepe, O.M.; Aga, M. The effect of job resourcefulness on role stress, emotional exhaustion and overall performance: A study of frontline bank employees. J. Financ. Serv. Mark. 2013, 18, 91-105. [CrossRef]

43. Yao, L.; Gao, J.; Chen, C.; Mu, D. How Does Emotional Labor Impact Employees' Perceptions of Well-Being? Examining the Mediating Role of Emotional Disorder. Sustainability 2019, 11, 6798. [CrossRef]

44. Grandey, A.A.; Gabriel, A.S. Emotional labor at a crossroads: Where do we go from here? Annu. Rev. Organ. Psychol. Organ. Behav. 2015, 2, 323-349. [CrossRef]

45. Bakker, A.B.; Schaufeli, W.B.; Leiter, M.P.; Taris, T.W. Work engagement: An emerging concept in occupational health psychology. Work Stress 2008, 22, 187-200. [CrossRef]

46. Fonseca, L.; Amaral, A.; Oliveira, J. Quality 4.0: The EFQM 2020 model and industry 4.0 relationships and implications. Sustainability 2021, 13, 3107. [CrossRef]

47. Bakker, A.B. An evidence-based model of work engagement. Curr. Dir. Psychol. Sci. 2011, 20, 265-269. [CrossRef]

48. Demerouti, E.; Bakker, A.B.; Gevers, J.M. Job crafting and extra-role behavior: The role of work engagement and flourishing. J. Vocat. Behav. 2015, 91, 87-96. [CrossRef]

49. Kahn, W.A. Psychological conditions of personal engagement and disengagement at work. Acad. Manag. J. 1990, 33, 692-724.

50. Wang, Q.; Weng, Q.; McElroy, J.C.; Ashkanasy, N.M.; Lievens, F. Organizational career growth and subsequent voice behavior: The role of affective commitment and gender. J. Vocat. Behav. 2014, 84, 431-441. [CrossRef]

51. Schmitt, A.; Den Hartog, D.N.; Belschak, F.D. Transformational leadership and proactive work behaviour: A moderated mediation model including work engagement and job strain. J. Occup. Organ. Psychol. 2016, 89, 588-610. [CrossRef]

52. Kim, J.; Lee, S.; Byun, G. Building a thriving organization: The antecedents of job engagement and their impact on voice behavior. Sustainability 2020, 12, 7536. [CrossRef] 
53. Rhoades, L.; Eisenberger, R. Perceived organizational support: A review of the literature. J. Appl. Psychol. 2002, 87, 698-714. [CrossRef]

54. Kurtessis, J.N.; Eisenberger, R.; Ford, M.T.; Buffardi, L.C.; Stewart, K.A.; Adis, C.S. Perceived organizational support: A meta-analytic evaluation of organizational support theory. J. Manag. 2017, 43, 1854-1884. [CrossRef]

55. Hur, W.M.; Han, S.J.; Yoo, J.J.; Moon, T.W. The moderating role of perceived organizational support on the relationship between emotional labor and job-related outcomes. Manag. Decis. 2015, 53, 605-624. [CrossRef]

56. Caesens, G.; Marique, G.; Hanin, D.; Stinglhamber, F. The relationship between perceived organizational support and proactive behaviour directed towards the organization. Eur. J. Work Organ. Psychol. 2016, 25, 398-411. [CrossRef]

57. Caesens, G.; Stinglhamber, F. The relationship between perceived organizational support and work engagement: The role of self-efficacy and its outcomes. Eur. Rev. Appl. Psychol. 2014, 64, 259-267. [CrossRef]

58. Miao, R.T. Perceived organizational support, job satisfaction, task performance and organizational citizenship behavior in China. J. Behav. Appl. Manag. 2011, 12, 105-127. [CrossRef]

59. Wen, J.; Huang, S.S.; Hou, P. Emotional intelligence, emotional labor, perceived organizational support, and job satisfaction: A moderated mediation model. Int. J. Hosp. Manag. 2019, 81, 120-130. [CrossRef]

60. Lee, J.S.; Back, K.J.; Chan, E.S. Quality of work life and job satisfaction among frontline hotel employees a self-determination and need satisfaction theory approach. Int. J. Contemp. Hosp. Manag. 2015, 27, 768-789. [CrossRef]

61. Choi, H.M.; Mohammad, A.A.; Kim, W.G. Understanding hotel frontline employees' emotional intelligence, emotional labor, job stress, coping strategies and burnout. Int. J. Hosp. Manag. 2019, 82, 199-208. [CrossRef]

62. Podsakoff, P.M.; MacKenzie, S.B.; Lee, J.Y.; Podsakoff, N.P. Common method biases in behavioral research: A critical review of the literature and recommended remedies. J. Appl. Psychol. 2003, 88, 879-903. [CrossRef] [PubMed]

63. Grandey, A.A. When "the show must go on": Surface acting and deep acting as determinants of emotional exhaustion and peer-rated service delivery. Acad. Manag. J. 2003, 46, 86-96.

64. Eisenberger, R.; Huntington, R.; Hutchison, S.; Sowa, D. Perceived organizational support. J. Appl. Psychol. 1986, 71, 500-507. [CrossRef]

65. Liang, J.; Farh, C.I.; Farh, J.L. Psychological antecedents of promotive and prohibitive voice: A two-wave examination. Acad. Manag. J. 2012, 55, 71-92. [CrossRef]

66. Schaubroeck, J.; Jones, J.R. Antecedents of workplace emotional labor dimensions and moderators of their effects on physical symptoms. J. Organ. Behav. 2000, 21, 163-183. [CrossRef]

67. Bentler, P.M.; Bonett, D.G. Significance tests and goodness of fit in the analysis of covariance structures. Psychol. Bull. 1980, 88, 588-606. [CrossRef]

68. Baron, R.M.; Kenny, D.A. The moderator-mediator variable distinction in social psychological research: Conceptual, strategic, and statistical considerations. J. Personal. Soc. Psychol. 1986, 51, 1173-1182. [CrossRef] 